\title{
Issues and Concerns in the Use of System Wide Accreditation as the Major Quality Control Mechanism in Nigerian Universities
}

\author{
Saliu, A. Danlad* \\ Department of Curriculum Studies and Educational Technology, Faculty of Education, University of Port \\ Harcourt
}

*Corresponding Author: Saliu, A. Danlad, Department of Curriculum Studies and Educational Technology, Faculty of Education, University of Port Harcourt

\begin{abstract}
This paper focuses on the problems and concerns in the of system wide accreditation as the quality control mechanism in Nigeria universities to investigate the meaning of quality control, why the NUC is saddled with taking care of the major control mechanism, guidelines for the creation of new universities, conclusion and recommendations.
\end{abstract}

\section{INTRODUCTION}

University education in Nigeria dates back to 1948 when the University College Ibadan was established with a student enrolment of 210 . The number of universities increase to six (6) between 1948 and 1971. Rapid expansion in the number of universities and student enrolment was witnessed from 1976 when 7 more universities were established by the federal government and at the end of 1992, eleven (11) additional universities were opened in various parts of the country including Abuja. Today, there are a total of 170 universities in the country (NUC, 2019). The phenomenal growth in the number of universities is accompanied with a rapid increase in students' enrolment.

The high demand for university education in Nigeria has made some universities to over-enroll students. Thus, ignoring the institutions' carrying capacities. The astronomical increase in students' enrolment results in overstretching of the existing facilities, overcrowded lecture halls, lowering of quality of teaching and research, examination malpractices, cultism and production of poor quality graduates. In an effort to control the quality of university education, the Federal Government of Nigeria established the National Universities Commission (NUC) as an agent to oversee and coordinate the university system. This paper, therefore, focuses on the concept of quality control, accreditation by National universities Commission as the major quality control mechanism in Nigerian Universities, issues and concerns of accreditation as major quality control mechanism

\section{The CONCEPT OF QUAlity CONTROL}

The concept of quality varies from that of providing special service to conforming to standards or to fitness of purpose (Akpan\&Esirah, 2005). Fadipe (2000); Whitely (2001) view quality in terms of worth, appropriateness, validity and relevance of resources available for the achievement of educational goals and priorities. UNESCO (2006) describes quality in higher education as being multidimensional and depends on the quality of staff, students, programs, infrastructure and academic environment. Viewed from this perspective, quality university education takes into consideration the quality and quantity of lecturers and students as inputs, quality and availability of textbooks and learning materials, quality and quantity of instructional facilities, quality and contents of instruction and curriculum, work-load, student- teacher ratio, quality of management and quality of monitoring, supervision and evaluation and quality outputs (Akpan, 2011). The National Universities Commission (NUC, 2006) defined quality control as the systematic review of educational programmes to ensure that acceptable standards of, education, scholarship and infrastructure are being maintained. (Ekong, 1998) described the concept of quality control as involving all the policies, systems and processes directed to ensuring the maintenance and enhancement of the quality of educational provision within 
an institution. The definition depicts that quality control involves the process of demonstrating excellence and value for money. It is therefore, a regulatory mechanism focusing on accountability and improvement, thus, establishing confidence in stakeholders that inputs, processes and outputs of educational system fulfill the expectations or measure up to minimum standards or requirements (Akpan\&Esirah, 2005). In the university system, quality control is the guarantee of confidence and certainty that standard and quality of a program run by the university are being maintained and enhanced. To achieve this, quality control system has to be established. This is the system by which a university confirms to itself and stakeholders in university education that the conditions are in place for students to achieve the standard it has set. Thus, it could be averred that quality control is about effectiveness in university education. While quality deals with "what", quality control deals with "how". For example, what type or kind of outputs (graduates) do we want to produce from universities? How do we go about producing the desired outputs? Quality control deals with measures, strategies and procedures to be employed to guarantee success in achieving the desired outputs. It deals with what people at different units, departments, faculties, institutes and schools within the university system, contribute to accepted standard of output quality. It therefore, involves a well coordinated quality control system. The universalization of quality control in higher education across the globe has made many countries of the world to set up agencies and organization to monitor, assess and evaluate the activities and programs of their universities to assure quality because the product of one university invariably become an employee in another university or industrial setting in another culture. Premised on this understanding, it is pertinent to look at the activities of the National University Commission in quality control in Nigeria universities.

\subsection{The National Universities Commission (NUC)}

The NUC was set up in 1962 following the recommendation of the Ashby Commission. Between 1962 and 1974, it was an interim body and largely limited in its capacity to perform because it was just regarded as an advisory body. The NUC was established deliberately to ensure that the value, goals and expectations within and around the university system are "protected and promoted" (Ofoegbu, 2004). The NUC metamorphosed into a statutory body through Decree No. 1 of

1974 and thus, had legal instrument to perform its functions. The National Universities Commission amendment Decree No. 49 of 1988 expanded the membership of the commission to thirty three (33) while the amendment Decree No. 10 of 1993 reconstituted the membership but reduced it to twentyone. The

NUC has five departments namely:

- Information and Communication Technology (ICT).

- Special Projects and Services.

- Academic Planning and Research.

- Physical Planning, Finance and Administration.

- Quality Assurance.

With these five departments, the basic functions of the NUC have been expanded to include:

- Inquiry into and advising the Federal Government on the recurrent and capital needs of the nation's university education.

- Receiving block grants from the Federal Government each year and allocating it to the universities based on the commission's advisable conditions.

- Advising the Federal Government on the establishment and location of new universities, creating new faculties and post graduate units in universities.

- Undertaking periodic review of the term and conditions of service of university staff.

- Recommending the establishment of new academic programs at both undergraduate and graduate levels to meet the national needs and objectives. 
- Establishing and maintaining the minimum academic standards in universities.

- Ensuring quality control for academic programs in universities

- Collating, analyzing and publishing information relating to university education and financing in and outside the country.

\subsection{Accreditation as a Major Quality Control Mechanism}

Accreditation is a process of self-study and external quality review used in higher education to scrutinize an institution and/or its programmes for quality standards and need for quality improvement. Accreditation involves the process of assessment and evaluation that ensures that a university and/or its programs are recognized as meeting minimum acceptable standards (Akpan, 2014). Maduewesi (2005) points out that accreditation aims at ensuring and maintaining education standards and institutional integrity.

The process is designed to determine whether or not an institution has met or exceeded the published standards (set by an external body such as a government, national quality assurance agency, or a professional association) for accreditation, and whether it is achieving its mission and stated purpose. The process usually includes a self evaluation, peer review and a site visit. Accreditation is the establishment or of the status, legitimacy or appropriateness of an institution, programme or module of study.

Accreditation standards and guidelines in Nigeria educational system is aimed at strengthening programme for quality control and quality improvement. It is a process that aids institutions in developing and sustaining effective educational programmes and assures the educational community, the general public, and other organizations that the accredited institution has met high standards of quality and effectiveness. The Council for Higher Education Accreditation (CHEA) in Washington, US defines accreditation as a process of external review used by higher education to scrutinize colleges, universities and educational programmes for quality control and quality improvement. However, the extent to which each tertiary institution accepts and fulfils the responsibilities inherent in this process is a measure of its concern for freedom and quality in higher education and of its commitment to strive for and achieve excellence in its endeavours.

According to United States Department of Education (USDE), there are two basic types of educational accreditation, one identified as "institutional" and one referred to as "specialized" or "programmatic"

Institutional accreditation normally applies to an entire institution, indicating that each of an institution's parts is contributing to the achievement of the institution's objectives, although not necessarily all at the same level of quality. In Nigeria, the major accrediting Commission for universities is the National Universities commission (NUC). The NUC performs institutional accreditation, as other national accrediting agencies do, such as the Board (NBTE). In Nigeria, specialized accreditation is a voluntary process and institutions choose to apply for accredited status. If accredited, such an institution agrees to abide by the standards of their accrediting agency and to regulate itself by taking responsibility for its own improvement.

As part of the efforts to ensure qualitative university education in Nigeria, the NUC was particular about ensuring accreditation of academic programmes in Nigerian universities in order to produce graduates who are relevant to the Nigerian economy.

Emphasis is laid on the quality of academic staff and students to be admitted and employed respectively. The Commission is committed to improving the quality of university programmes through injection of requisite inputs as well as assuring quality process and outputs based on the decree 49 of 1988 that widen its scope. The National Universities Commission is charged to embark on accreditation as the major quality control in Nigerian universities.

In Nigeria, the National Universities Commission (NUC) provides a team of academic experts and members of professional bodies who utilize the minimum academic standards (MAS) documents as 
Issues and Concerns in the Use of System Wide Accreditation as the Major Quality Control Mechanism in Nigerian Universities

benchmarks for the accreditation of university programs. Accreditation in Nigerian universities features such criteria as:

\section{Criteria Maximum score in Percentage}

\begin{tabular}{|l|l|l|}
\hline a) & Staffing & 32 \\
\hline b) & Academic content & 23 \\
\hline c) & Physical facilities & 25 \\
\hline d) & Library & 12 \\
\hline e) & Funding & 5 \\
\hline f) & Employer's rating of graduates & 3 \\
\hline & Total & $\mathbf{1 0 0}$ \\
\hline
\end{tabular}

Each criterion has component indices with varying weightings as contained in the manual of accreditation procedures for academic programs in Nigerian universities.

The NUC in an effort to facilitate the process of accreditation in Nigerian universities develops formats to guide the exercise. These formats include Program Evaluation Form, Accreditation Panel Report Form, Self-study Form and Manual of Accreditation Procedures which are used during accreditation exercises. Accreditation is done every five years and involves three (3) stages namely, self study, site visit and peer review and reporting of outcome. The report of the accreditation panel determines the award of accreditation status in terms of "full" or "interim" or "denied Accreditation".

\subsection{Full Accreditation}

This means that a program has met the set out guidelines with a total score of $70 \%$ and above in the various areas of quality considered by the accreditation team.

\subsection{Interim Accreditation}

This means that the programs of study is not highly rated in the various areas of quality and has a total score $60-69 \%$. Such a program could be re-visited within -3 years.

\subsection{Denied Accreditation}

This means that the program has a total score of less than $60 \%$ in various areas of quality and the entire program will be re-visited within aperiod of 1-3 years. If an academic program is given denied accreditation status, the NUC will communicate this information to the Vice Chancellor of the university concern, stating reasons for accessing the program denied accreditation and the steps to be taken to bring the program up to minimum academic standards for full accreditation status. In addition the university ceases to admit student into that program with effect from the next academic year. Through accreditation, the quality of university education in Nigeria is enhanced. However plans are under way for institutional accreditation in Nigeria universities.

Issues and concerns in the use of system wide accreditation as the major quality control mechanism in Nigerian universities includes but not limited to the following:

The issue of minimum academic standards (MAS), establishment of new academic programs, establishment of new universities, uniform grading system, ranking of universities, establishment of virtual library and virtual institute of higher education pedagogy, the carrying capacity.

\section{Minimum ACADEMiC STANDARdS (MAS)}

The first role of the NUC was the establishment of the Minimum Academic Standard (MAS) in 1989. This document was a result of wide consultations with universities and expert academics in the broad disciplines taught in Nigerian universities. In 2001, the NUC organized stakeholders' conference on curriculum review in which experts in various disciplines and professional bodies drew up subject Benchmark statements for all undergraduate programs in the universities. The MAS documents provide specification for minimum floor space for lectures, minimum laboratory/ studio space and facilities per student, minimum number and quality of staff, minimum floor, sitting and required equipment for the library, staff/ student ratio for effective teaching and learning for each discipline, minimum entry/ graduation requirements for each discipline program as well as the curriculum for each academic discipline/ program. 
In 2004 the Minimum Academic Standards (MAS) was merged with the Benchmark statements into a single document called Benchmark Minimum Academic Standards (BMAS). This document now serves as an excellent tool for quality assurance and accreditation of academic programs in Nigeria universities.

\subsection{Establishment of New Universities}

The NUC has put in place guidelines for establishment of new universities. These guidelines are necessary to ensure quality right from inception of the institutions. There is a standing committee on Establishment of Private Universities to process all applications for the opening of new private universities and to ensure that the criteria and requirements for establishment of academic activities (Uvah, 2005). In this way, the NUC ensures that the new university education has adequate human and material resources to carry out the delivery of university education. Thus, guaranteeing quality university education. State governments in Nigeria also have the right to establish universities because education is in the concurrent list in the Nigeria constitution where both the federal and state governments have jurisdiction. Before any state government can open a university, it must receive prior clearance from the NUC. The Commission will visit and meet with relevant officials of the state government and advise them on the basic requirements for the establishment of a new university and how to achieve quality in university education for compliance. If complied, the institution earns federal government recognition.

\section{Establishment of NeW ACAdemic Programs}

The establishment of new academic programs in universities follows a rigorous internal process. The proposals emanate from the departments and are carefully scrutinized by the faculty boards before they are sent to the committee of Deans for further screening. When this committee is satisfied with all sections of the proposal, it is then sent to the senate for consideration and approval. Before the implementation of the programs, the universities concerned must seek and obtain approval from NUC.

In this way, the NUC ascertains the claims made by the universities in their submissions to the commission about their readiness to establish the proposed program, without which the program cannot commence.

\subsection{Uniform Grading System}

The NUC has developed a course system and Grade Point Average (GPA) documents for use in the Nigerian university system. The adoption of this document by the universities has brought uniformity in the grading system of all the universities (Ojedele\&Ilusanya, 2006).

\subsection{Ranking of Universities}

Another bold step taken by NUC to ensure quality of performance, facilities and awards in Nigerian universities is in the ranking of universities. The commission made uses accreditation results to rank Nigerian universities based on performance of their programs. The ranking was based on a multiple set of performance indicators which included academic excellence, governance, research and adherence to the minimum academic standards and approved national norm.

Universities with top level performance were encouraged to strive to maintain and enhance the quality of their programs, while those at the bottom of their performance were expected to take necessary steps to remedy the deficiencies identified in order to improve upon the qualities of the programs.

According to Uvah, (2005) the aim of ranking of Nigerian universities by NUC is to encourage healthy competition in maintenance of academic quality and good governance.

\subsection{Establishment of Virtual Library and Virtual Institute for Higher Education Pedagogy}

The National Virtual Library project embarked upon by the NUC is another milestone to ensuring quality of university education in Nigeria. The aim is to improve the quality of teaching and research in universities and other higher institutions in the country. The virtual library project provides access to current textbooks and journals not available in our university libraries. It also provides access to national and international libraries and other information resources held by global network of on-line libraries through shared digital technology. 
The Virtual Institute for Higher Education Pedagogy (VIHEP) established by NUC is aimed at improving the quality of teaching and learning in Nigeria universities. The purpose is to improve the knowledge and skills of academic staff in pedagogy. It is an on-line training program through internet.

The objective of VIHEP include:

- To provide academic staff with internet-based training on modem methods of teaching and learning in higher institutions.

- To enhance the skills and knowledge of academic staff on such issues as teaching of larges class, effective use of limited resources, modern methods of assessment and evaluation of students' performance, basic guidance and counseling techniques, basic skills of curriculum development and for writing grant winning proposals.

- To share experience among academic staff in Nigerian universities on best practices in university teaching and how to deal with such academic vices as examination malpractice, cultism and plagiarism (Uvah, 2005).

\section{The CARRYing CAPACITY}

The carrying capacity is a strategy initiated by the NUC to control the enrolment of students in Nigerian universities in order to deliver quality education. The carrying capacity is the maximum number of students that the institution can sustain for qualitative education based on available human and material resources. The human resources are the teachers defined in terms of quality and quantity. The material resources include the classrooms, libraries, laboratories, offices and other support physical resources for teaching and research. It is worth noting that a university with a negative deviation from its carrying capacity has over-enrolled and this could have a negative impact on the quality of university education. With the introduction of the carrying capacity, the enrolment of students is greatly controlled and the average number of students' per teacher reduced to manageable limit. This approach, therefore, enhance quality graduates as there is an improved teacher-student relationship (Akpan\&Esirah, 2005).

In addition to the above issues, the NUC also encourages Nigerian universities to establish and maintain a culture of strategic planning and management. Through this method, the universities are better resourced, better managed and better focused. The strategic planning and management help universities to realize their teaching, learning and research objectives. The NUC also encourages universities to establish their internal quality control mechanisms such as fresh students screening committees, departmental and faculty academic boards that report to senate. The senate oversees matters germane to entrenchment, maintenance and enhancement of quality in the university. The establishment of the external examiner system in universities involves appointment of external examiners. These are independent academic experts drawn from other universities to provide impartial advice on performance in relation to particular programs. Thy report directly to the heads of institutions. There is also the Appointment and Promotion Committee that handles the appointment and promotion of all categories of staff in a university based on the stipulated guidelines. All these strategies are aimed at maintaining and enhancing academic standards, quality and accountability.

\section{CONCLUSION AND RECOMMENDATIONS}

System wide accreditation as the major quality control mechanism in universities and other higher institutions has become a matter of global interest. It is a mechanism through which universities can establish that their graduates are competitive and can meet internationally accepted standards and excellence. The issues and concerns of the National Universities Commission (NUC) in assuring quality in university education in Nigeria has been outlined to include establishment of Minimum Academic Standards (MAS), procedural guidelines for establishment of new universities and programs, uniform grading system, ranking of universities etc. These steps taken by the NUC depicts that Nigeria is not lagging behind in her quest to provide quality university education to her citizenry and to ensure that our university graduates compete favorably well internationally. Although quality is a multifaceted issue comprising various components, the paper recommends the input-process-output framework for assessing quality of university education because it involves a step-by-step assessment of the major components of educational quality. The paper also recommends that the NUC should set 

in Nigerian Universities

up a monitoring team which would ensure that universities stay within the quota approved for them for admission so as to keep pace with their carrying capacities.

The commission should make the ranking of Nigerian Universities a continuous process because it encourages healthy competition in maintenance of academic quality and efficient management.

\section{REFERENCES}

[1] Akpan, C (2019). Quality Assurance in Nigerian Universities: the role of the National Universities Commission. Proceedings of INTED 2014 Conference 10th 12th March 2014 Valencia, Spain. ISBN: 97884-84-616-84 12-0

[2] Akpan, C. P. \&Esirah, E. (2005).Strategies for Realistic Quality Assurance in Knowledge Generation in Tertiary Institutions in Nigeria. In D.N. Eze\& N. Onyegegbu (eds.) Knowledge Generation and Dissemination: Issues and Challenges in Nigerian Universities. Enugu, Pearl and Gold.

[3] Akpan, C. P. (2011). Quality Assurance Management in Higher Education.In S. U. Bassey\& U. U. Bassey (eds.) Management of Higher Education in Africa.Uyo, Nigeria: Abaam Publishers.

[4] Ekong D. (1998). Quality: trends from UNESCO Regional Consultations on Higher Education. Paris: UNESCO, Paper of Synthesis of Regional Conference.

[5] Fadipe, I. O. (2000). Efficiency indicators for quality control in Nigerian school system in J. O. Fadipe\& D.K. Ojedele (eds.), Management of NigerianEducation: Personnel Administration and Quality in Education. Nigeria: NIEPA.

[6] Ijeoma, M. E. \&Osagie, R. O (2005).Strategies for Quality Assurance in Higher Education.Nigerian Journal of Education Administration and Planning. 5. (2); pp. 271-28 1.

[7] Maduewesi, E. J. (2005). Benchmarks and Global Trends in Education. Benin City, Dasylva.

[8] National Universities Commission (2006). "Accreditation of Nigeria universities".

[9] National Universities Commission (2009). Weekly Bulletin, 4(46), November, 9.

[10] National Universities Commission (2019). Development of Universities in Nigeria.

[11] Retrieved from http//www. campusbiz.com.ng

[12] Ofoegbu, F.I. (2004). Agencies, Board and Commissions in Nigerian Education system. In N.A. Nwagwu, M.E. Ijeoma\& C. C. Nwagwu (eds.) Organization and Administration of Education; Perspective and Practice, Benin City, Nigeria: Fiesta.

[13] Ojedele, P \&Ilusanya, G (2006).Planning and Policy of Higher Education in Nigeria. In J. B. Babalola, A.O. Ayeni, S.O. Adedeji, A.A. Suleiman \&M.O. Arikewuyo (eds.), Educational Management: Thought and Practice.Ibadan, Codat.

[14] UNESCO (1998). Higher Education in the 21st Century: Vision and Action; Working Document. World Conference on Higher Education, Paris: UNESCO.

[15] Uvah, I. I (2005).Quality Assurance and Institutional Stability in the Nigerian University System.Nigerian Journal of Educational Administration and Planning 5 (1); pp. 2-20.

[16] Whitely, P. (2001). Quality Assurance: It's Centrality to the Administration of Caribbean Tertiary Level Institutions. The Caribbean Education Manual VT; pp.13-24.

Citation: Saliu, A. Danlad. "Issues and Concerns in the Use of System Wide Accreditation as the Major Quality Control Mechanism in Nigerian Universities". International Journal of Humanities Social Sciences and Education (IJHSSE), vol. 7, no.1, 2020, pp. 42-48. doi: http://dx.doi.org/10.20431/2349-0381.0701005.

Copyright: () 2020 Authors. This is an open-access article distributed under the terms of the Creative Commons Attribution License, which permits unrestricted use, distribution, and reproduction in any medium, provided the original author and source are credited. 